\title{
Capsaicin sensitivity in patients with chronic cough- results from a cross-sectional study
}

\author{
Ewa Ternesten-Hasséus ${ }^{1 *}$, Christel Larsson², Sven Larsson ${ }^{3}$ and Eva Millqvist ${ }^{1}$
}

\begin{abstract}
Background: A subgroup of patients with chronic cough is recognised as having airway symptoms resulting exposure to chemicals and scents related to enhanced cough sensitivity to inhaled capsaicin. Sensory hyperreactivity, which has an estimated prevalence of more than $6 \%$, is one possible explanation for the symptoms experienced by these patients. We hypothesized that a number of patients diagnosed with chronic unexplained cough also have coughing provoked by chemical irritants associated with augmented capsaicin cough reaction, but the extent of such a relation is not known. One aim of the present study was to analyse cough sensitivity to inhaled capsaicin in patients with chronic unexplained cough. Another aim was to compare capsaicin sensitivity in individuals with chemically induced coughing (the chemical-sensitive group) to capsaicin sensitivity in those without such chemical sensitivity (non-sensitive group).

Methods: Fifty-six participants from an earlier cross-sectional study of 62 patients with chronic unexplained cough were asked to participate in this study: 33 were chemical-sensitive and 23 were non-sensitive. Each participant visited the clinic once and performed a capsaicin inhalation test with one of two inhalation devices. The number of coughs, induced airway symptoms, and spirometry results were recorded.

Results: Thirty-nine of the invited patients participated in the study, with 32 in the chemical-sensitive group (21 women, 11 men), and 7 in the non-sensitive group (4 women, 3 men). The chemical-sensitive patients coughed significantly more on inhaling capsaicin, and had significantly more other airway symptoms compared to those in the non-sensitive group. Women coughed significantly more than men after receiving the higher concentration of capsaicin.

Conclusions: Environmental irritants often trigger chronic unexplained cough. The current findings confirm that this sensitivity is related to enhanced capsaicin cough sensitivity and indicates more involvement of airway sensory nerves in the pathophysiology of the disease than in cough without evident trigger factors.
\end{abstract}

Keywords: Cough, Chemical sensitivity, Capsaicin, Sensory hyperreactivity

\section{Background}

About $10-38 \%$ of patients seeking medical care in respiratory clinics report coughing as a symptom [1,2]. Individuals suffering from cough, show a high level of morbidity and a high rate of healthcare utilization, and cough has a negative impact on patients' health-related quality of life [3-6]. Cough is regarded as chronic when it persists for more than 8 weeks [7]. Common causes of chronic cough include asthma, gastroesophageal reflux disease (GERD), and post-nasal drip syndrome [8]. After

\footnotetext{
* Correspondence: ewa.ternesten@lungall.gu.se

'Department of Allergology, Institution of Internal Medicine, the Sahlgrenska Academy at University of Gothenburg, Gothenburg, Sweden

Full list of author information is available at the end of the article
}

all possible underlying causes of cough have been excluded and the patients have been treated according to current guidelines, a group of patients, mainly female, remains that can be labelled as having chronic refractory unexplained cough. This cough is often triggered by talking, laughing, singing, or strong chemicals and scents from perfume, cigarette smoke, and cooking $[9,10]$. More knowledge is needed about cough induced by such irritants.

Sensory hyperreactivity (SHR) is one explanation for cough and other airway symptoms induced by exposure to chemicals and scents $[11,12]$. However, the extent to which SHR could help explain the symptoms experienced
C Bïomed Central

(c) 2013 Ternesten-Hasséus et al.; licensee BioMed Central Ltd. This is an Open Access article distributed under the terms of the Creative Commons Attribution License (http://creativecommons.org/licenses/by/2.0), which permits unrestricted use,

distribution, and reproduction in any medium, provided the original work is properly cited. 
by patients with chronic unexplained cough is not well known. Common symptoms of SHR are cough, heavy breathing, difficulty getting air, phlegm, throat irritation, hoarseness, rhinorrhoea, and eye irritation [11-13]. SHR is most common among women (70\%), and a Swedish population-based study estimated its prevalence to be more than 6\% among adults [14]. Patients with SHR can be identified through a capsaicin provocation test. Several studies have shown this test has good short-term and long-term reproducibility and the ability to distinguish between patients with SHR and those with asthma and those who are healthy controls [11-13,15].

Capsaicin, the main pungent ingredient in chilli, is a well-known cough-inducing agent when inhaled [16-19]. It is a noxious and odourless vanilloid, which stimulates the unmyelinated C-fibres of the sensory nervous system and produces a burning sensation by activating the ion channel transient receptor vanilloid subunit 1 (TRPV1) [20]. The TRPV1 channel is activated not only by capsaicin, but also by noxious stimuli and heat; it is potentiated by extracellular acidic $\mathrm{pH}$, and interacts with vanilloid compounds [21]. Patients with chronic cough have increased expression of TRPV1 and a significant correlation between capsaicin response and the number of TRPV1-positive nerves [22]. A heightened cough sensitivity to inhaled capsaicin has been found in patients with chronic cough, in cases where the cause of the cough is known and where it is unknown [23].

We hypothesized that a number of patients diagnosed with chronic unexplained cough also have coughing provoked by chemical irritants associated with augmented capsaicin cough reaction but the extent of such a relation is not known. To further explore this, a capsaicin inhalation test could be applied. One aim of the present study was to analyse cough sensitivity to inhaled capsaicin in patients with chronic unexplained cough. The patients had been selected from an earlier cross-sectional study [6]. Another aim was to compare capsaicin sensitivity in individuals with chemically induced airway symptoms (the chemical-sensitive group) to capsaicin sensitivity in those without such chemical sensitivity (non-sensitive group).

\section{Methods}

\section{Patients}

Fifty-six patients from an earlier cross-sectional study that included 62 patients with chronic unexplained cough were randomly selected and invited to participate in this study [6]. The group included 33 chemical-sensitive patients and all of the 23 non-sensitive individuals. The earlier study had already excluded all patients with diseases such as asthma, chronic obstructive pulmonary disease and pulmonary fibrosis that could cause cough and all patients diagnosed with allergy, rhinitis, post-nasal drip syndrome, or any kind of GERD, those making any use of angiotensin-converting enzyme inhibitors or medication for GERD, and current smokers. This study excluded anyone who was pregnant or breastfeeding.

\section{Study design}

The participants were contacted by phone. Informed consent was obtained from all participants after they were provided with verbal and written information. The study was approved by the Regional Ethical Review Board of Gothenburg, Sweden.

The participants visited the clinic once and all of them were again screened using a local questionnaire that asked whether they had airway symptoms from chemicals and scents (yes/no) [6]. None of the patient had performed a capsaicin inhalation test before they were included in the study. Provocations were not performed in patients who had experienced respiratory infections during the past month. Before the capsaicin provocations, all medication was withheld for at least $6 \mathrm{~h}$.

The capsaicin challenges were performed with a standardized method [11-15] with one of two different air-driven devices: Pari Boy (Paul Ritzau Pari-Werk, GmbH, Starnberg, Germany) or Maxin MA3 (Clinova Medical AB, Malmö, Sweden). The two different inhalation devices were used because the allergy clinic switched from using the Pari Boy to using the Maxin MA3 over the period of studies. These devices are compatible in terms of the limits set for a positive capsaicin inhalation test, but use different capsaicin concentration levels [15].

In each challenge the participant inhaled saline followed by two concentrations of capsaicin, the second being stronger than the first. The order of the given concentrations was known by the nurse performing the tests but the patients were not told that the capsaicin concentrations would increase during the provocations. The total time for each provocation was about 35 minutes.

In accordance with the earlier established limits for capsaicin cough sensitivity [12,14], the cut-off values for a positive capsaicin inhalation test for the diagnosis of SHR was set to 10 coughs at the lower capsaicin concentrations $(0.4$ and $0.06 \mu \mathrm{mol} / \mathrm{L})$ or 35 coughs at the higher capsaicin concentrations $(2.0$ and $0.3 \mu \mathrm{mol} /$ L), with both the devices $[12,14,15]$.

\section{Capsaicin provocation}

A stock solution of capsaicin $(1 \mathrm{mmol} / \mathrm{L}$ in ethanol [99.5\%] from Sigma-Aldrich Sweden AB, Stockholm, Sweden) was prepared. From this stock solution, aqueous provocation solutions were prepared in accordance with earlier studies; the solutions were 0.4 and $2.0 \mu \mathrm{mol} /$ $\mathrm{L}$ for the Pari Boy device and solutions of 0.06 and 0.3 $\mu \mathrm{mol} / \mathrm{L}$ for the Maxin MA3 device. The number of 
coughs was counted manually for $10 \mathrm{~min}$ from the start of inhalation of each provocation solution $[13,15]$.

In the case of the Pari Boy device, the device was filled first with $1 \mathrm{~mL}$ of saline and then two capsaicin concentrations $[11-13,15]$. The participants were instructed to inhale with tidal volume breathing without a nose-clip, to completion or for a maximum of $6 \mathrm{~min}$, following by a 4 min rest.

The Maxin MA3 device was filled first with $2 \mathrm{~mL}$ saline and then the two capsaicin concentrations. The device nebulizes continually, and provides a fixed constant flow of $0.25 \mathrm{~mL} / \mathrm{min}$. The participants were instructed to inhale with tidal volume breathing without a noseclip for $4 \mathrm{~min}$, followed by $6 \mathrm{~min}$ rest, consequently they inhaled a total of $1 \mathrm{~mL}$ provocation solution [15].

Before and after the capsaicin provocation, the participants evaluated their symptoms on a scale of $0-3(0$, no symptoms; 1 , mild symptoms; 2 , moderate symptoms; and 3, severe symptoms). Eight symptoms were analysed: heavy breathing, difficulty getting air, chest pressure, phlegm, throat irritation, hoarseness, rhinorrhoea, and eye irritation $[11,24,25]$.

Forced expiratory volume during $1 \mathrm{~s}\left(\mathrm{FEV}_{1}\right)$ was measured before and after each capsaicin provocation (Vitalograph, Buckingham, UK), and the highest of two values was recorded.

\section{Statistical methods}

All data were analysed using version 17 of the SPSS software package (SPSS, Inc., Chicago, IL, USA). Data are presented as mean values with standard deviation (SD) and median values. Results were considered significant at a $p$ value of $<0.05$. The Mann-Whitney $U$-test was used for non-paired data, and the Wilcoxon signed-rank test for paired data.

In accordance with dose-response relationships seen in earlier studies, missing data for participants whose provocation was halted due to excess coughing were filled in by doubling the number of coughs evoked by the lower capsaicin concentrations to represent the cough response to the higher capsaicin concentrations $[11,13,15]$.

\section{Results}

Of the 56 patients invited to participate, 17 were excluded due to recovery from their coughing: 2 were in the chemical-sensitive group $(n=33)$ and 11 were in the non-sensitive group $(n=23)$. In the non-sensitive group, 3 others were excluded because of difficulty in taking time away from work, and 1 because of azithromycin treatment for airway symptoms. All of the chemicalsensitive patients reported persistent sensitivity and one of the previously non-sensitive patients reported symptoms from chemicals and scents and was reassigned to the chemical-sensitive group.

The final analyses was done on the data from 39 patients, 32 (mean age 54.7 [10.8]) in the chemicalsensitive group (21 women and 11 men), and 7 (mean age 49.4 [19.5]) in the non-sensitive group (4 women and 3 men). The demographic data of the study group are shown in Table 1. All patients except for two had had a negative methacholine inhalation test within the last five years, in accordance with international guidelines [26,27]. Of the 39 patients, 5 regularly used inhaled corticosteroids, 4 inhaled $\beta_{2}$-agonists, 1 inhaled anticholinergic, and 8 used morphine derivate syrup.

\section{Capsaicin provocation}

Nine patients in the chemical-sensitive group had undergone the capsaicin inhalation test four years earlier with the Pari Boy device [11-13,15], and that data were used in this study. The remaining 30 patients ( 23 from the chemical-sensitive group, and 7 from the non-sensitive group) were tested using the Maxin MA3 device [15].

All 39 patients tried to inhale the lower concentrations of capsaicin ( 0.4 and $0.06 \mu \mathrm{mol} / \mathrm{L}$ for the Pari Boy device and the Maxin MA3 device respectively); 5 patients in the chemical-sensitive group discontinued the provocation because of having more than 35 coughs. All patients in the non-sensitive group inhaled both the low and the high capsaicin concentrations. The chemical-sensitive group coughed significantly more than the non-sensitive group on the lower concentrations of capsaicin $(p<$ $0.05)$. In the chemical-sensitive group, the median number of coughs was 13 for the lower concentrations (0.4 or $0.06 \mu \mathrm{mol} / \mathrm{L}$ ) and 37.5 for the higher concentrations $(2.0$ or $0.3 \mu \mathrm{mol} / \mathrm{L})$. The corresponding values for the non-sensitive group were 5 and 15 , respectively. The results of the capsaicin provocations are presented in Figure 1.

Twenty two $(69 \%)$ of the patients in the chemicalsensitive group had a positive capsaicin inhalation test, and met the diagnostic criteria for SHR $[12,14]$. In the

Table 1 Demographic data for 39 patients with chronic cough

\begin{tabular}{ll}
\hline Characteristics & Patients $(\mathbf{n}=\mathbf{3 9})$ \\
\hline Sex, female/male $(\mathrm{n})$ & $25 / 14$ \\
Chemical-sensitive/non-sensitive $(\mathrm{n})$ & $32 / 7$ \\
Age, years & $53.8(12.6)$ \\
Duration of cough symptoms, years & $9.4(6.2)$ \\
Smoking status ( $\mathbf{n})$ & \\
Never/previous & $24 / 15$
\end{tabular}

Data are presented as mean and standard deviation (SD) for age and duration of cough symptoms, and otherwise as number (n). 


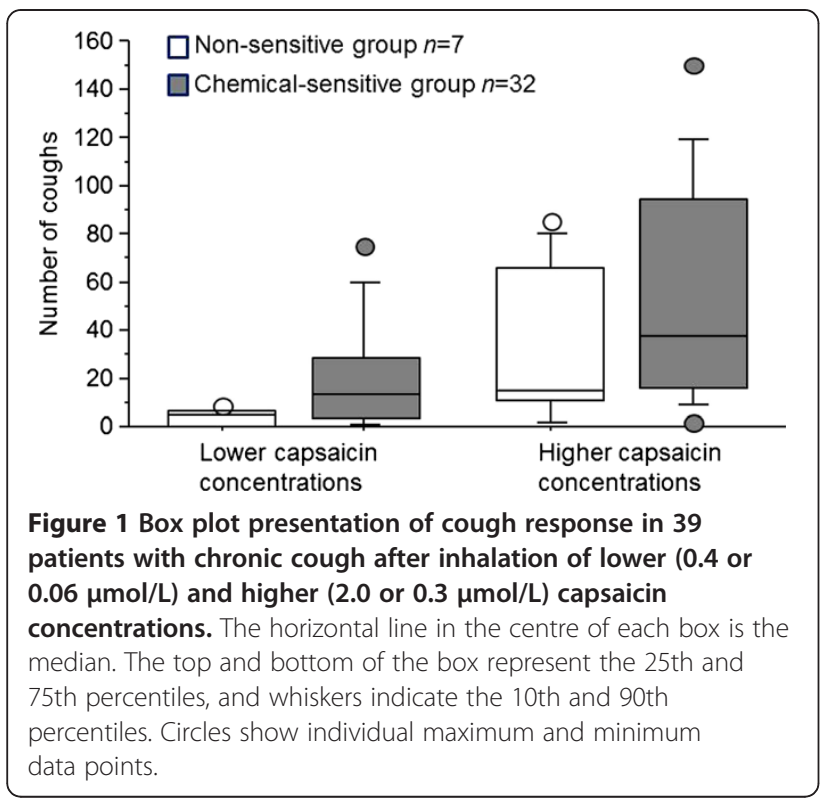

non-sensitive group, 3 of 7 patients (43\%) had a positive capsaicin inhalation test.

Women coughed significantly more than men on inhaling the higher concentrations of capsaicin $(p<0.05)$. For women the median number of coughs was 10 at the lower concentrations of capsaicin and 55 at the higher concentrations. The corresponding values for men were 6.5 and 23.5 respectively.

The capsaicin provocation also induced significantly greater symptoms in the chemical-sensitive group for heavy breathing $(p<0.001)$, difficulty getting air $(p<$ $0.01)$, chest pressure $(p<0.05)$, phlegm $(p<0.05)$, throat irritation $(p<0.01)$, hoarseness $(p<0.01)$, rhinorrhoea $(p$ $<0.001)$, and eye irritation $(p<0.05)$. In the nonsensitive group, the capsaicin provocation induced significantly more $(p<0.05)$ throat irritation.

The basic mean $\mathrm{FEV}_{1}$ was $102.4 \%$ (18.4) of predicted value in the chemical-sensitive group and 103.8\% (14.9) of predicted value in the non-sensitive group (ns), and did not change after any capsaicin provocation.

\section{Discussion}

The main finding of this study was that environmental irritants are often triggering factors in chronic unexplained cough and cough sensitivity to inhaled capsaicin was higher in chemical-sensitive patients than in nonsensitive patients. We also found that $22(69 \%)$ of the patients in the chemical-sensitive group had a positive capsaicin inhalation test, and met the diagnostic criteria for SHR [12,14]. In the non-sensitive group, only 3 of 7 patients (43\%) had a positive capsaicin inhalation test. Further, in comparison to previous studies the results indicate higher capsaicin sensitivity in the non-sensitive group than in earlier tested healthy controls $[28,29]$, but the present non-sensitive group is too small to draw any major conclusions. The study included twice as many women as men, and the study results are in accordance with previous reports of women being over-represented in cough clinics [9] and being more sensitive to inhaled capsaicin $[30,31]$.

A total of 13 patients had been excluded from participating because they had recovered from their cough. Eleven belonged to the non-sensitive group, constituting $48 \%$ of the non-sensitive individuals. This indicates a possibility of recognising a group of cough patients who have symptoms induced by environmental irritants and who are at risk of having the problems last for several years. However, although increasing evidence suggests environmental irritants are important factors in chronic cough [10,32-34], larger groups of patients need to be studied to find out whether chemical sensitivity is essential for long-lasting symptoms to occur.

The use of two devices, the Pari Boy and Maxin MA3 could be perceived as a limitation. However, an earlier study showed that the Pari Boy and the Maxin MA3 device, which we used in the present study, can be used interchangeably to estimate levels of neural sensory reactivity, and there was good agreement between the cough results of capsaicin with the two devices [15]. Each provocation method had also a good ability to distinguish patients with SHR from healthy controls, although the Maxin MA3 device showed even higher degree of discriminative ability between patients with SHR and healthy control $[11,15]$.

The capsaicin inhalation test is non-specific because of the huge variation in capsaicin cough sensitivity among healthy individuals and in the different conditions affecting the airways $[18,35]$. The patients in the present study were carefully examined and other causes of cough were excluded. To avoid bias, international guidelines recommend capsaicin concentrations be given randomly, and that saline be randomly interspersed between incremental concentrations of capsaicin [36]. Previous studies have, however, shown that the order in which capsaicin concentrations are given is of importance for the cough outcome of capsaicin provocations $[14,18]$ and that in patients with SHR even inhalation of saline induced coughing [11,37]; these findings influenced our choice of method, with first saline and then low and high concentration of capsaicin being given. Furthermore the participants had not previously been tested with capsaicin and they were not told that the capsaicin concentrations would increase during the provocation. In our experience, the capsaicin inhalation test used herein with tidal breathing is a stable and reproducible method, and represents an objective test to measure sensory reactivity in the airways. The limits used for a positive capsaicin inhalation test were in accordance 
with those used previous studies in patients with SHR $[12,14]$.

Researchers have sharply disagreed on the cause of chronic unexplained cough [38,39], which included postnasal drip syndrome [1] and GERD [40,41]. During the last decade, however, a more common view seems to have developed [42] and the post-nasal drip syndrome is now often replaced with a more general description, 'upper airway cough syndrome' [43]. The upper and lower airways are viewed as being closely related and complementing each other with regard to reflexes [44-46]. This close connection is also evident in regard to chronic cough. The cough hypersensitivity syndrome is a new paradigm that accounts for unexplained cough and includes several groups of chronic cough patients, both those with symptoms that may indicate a reflux disease and those with a general hypersensitivity towards, for example, environmental irritants [32,33,47]. The current study demonstrates that an association exists between the upper airways and chronic cough, because many patients also had rhinitis symptoms after the capsaicin provocations. It also shows a general airway hypersensitivity linked to increased capsaicin cough sensitivity.

\section{Conclusions}

Environmental irritants often trigger chronic unexplained cough. The current findings confirm that this sensitivity is related to enhanced capsaicin cough sensitivity and indicates more involvement of airway sensory nerves in the pathophysiology of the disease than in cough without evident trigger factors.

\section{Abbreviations}

$\mathrm{FEV}_{1}$ : Forced expiratory volume during one second; GERD: Gastroesophageal reflux disease; Ns: Not significant; SD: Standard deviation; SHR: Sensory hyperreactivity; TRPV1: Transient receptor potential vanilloid type 1.

\section{Competing interests}

The authors declare that they have no competing interests.

\section{Authors' contributions}

All the authors participated in the design of the study. ETH coordinated and analysed the data and drafted the manuscript. EM analysed the data and drafted the manuscript. CL and SL helped to draft the manuscript. All authors have read and approved the final manuscript.

\section{Acknowledgements}

This study was supported by grants from the Regional Health Care Authority of West Sweden, the Asthma and Allergy Association's Research Foundation, and the Swedish Heart and Lung Foundation. We are thankful to Inger Winberg for help with the recordings, and Marianne Wallgren for help with the capsaicin preparations.

\section{Author details}

${ }^{1}$ Department of Allergology, Institution of Internal Medicine, the Sahlgrenska Academy at University of Gothenburg, Gothenburg, Sweden. ${ }^{2}$ Department of Otorhinolaryngology, Central Hospital, Skövde, Sweden. ${ }^{3}$ Department of Respiratory Medicine, Institution of Internal Medicine, the Sahlgrenska Academy at University of Gothenburg, Gothenburg, Sweden.
Received: 6 August 2012 Accepted: 18 February 2013

Published: 28 February 2013

\section{References}

1. Irwin RS, Curley FJ, French CL: Chronic cough. The spectrum and frequency of causes, key components of the diagnostic evaluation, and outcome of specific therapy. Am Rev Respir Dis 1990, 141:640-647.

2. McGarvey LP, Heaney LG, MacMahon J: A retrospective survey of diagnosis and management of patients presenting with chronic cough to a general chest clinic. Int J Clin Pract 1998, 52:158-161.

3. French $\mathrm{CL}$, Irwin RS, Curley FJ, Krikorian CJ: Impact of chronic cough on quality of life. Arch Intern Med 1998, 158:1657-1661.

4. Everett CF, Kastelik JA, Thompson RH, Morice AH: Chronic persistent cough in the community: a questionnaire survey. Cough 2007, 3:5.

5. Young EC, Smith JA: Quality of life in patients with chronic cough. Ther Adv Respir Dis 2010, 4:49-55.

6. Ternesten-Hasseus E, Larsson S, Millqvist E: Symptoms induced by environmental irritants and health-related quality of life in patients with chronic cough - a cross-sectional study. Cough 2011, 7:6.

7. Morice AH, Fontana GA, Sovijarvi AR, Pistolesi M, Chung KF, Widdicombe J, O'Connell F, Geppetti P, Gronke L, De Jongste J, Belvisi M, Dicpinigaitis P, Fischer A, McGarvey L, Fokkens WJ, Kastelik J: The diagnosis and management of chronic cough. Eur Respir J 2004, 24:481-492.

8. Morice AH: Epidemiology of cough. Pulm Pharmacol Ther 2002, 15:253-259.

9. Haque RA, Usmani OS, Barnes PJ: Chronic idiopathic cough: a discrete clinical entity? Chest 2005, 127:1710-1713.

10. Vertigan $A E$, Gibson $P G$ : Chronic refractory cough as a sensory neuropathy: evidence from a reinterpretation of cough triggers. J Voice 2011, 25:596-601.

11. Millqvist $E$, Bende $M$, Löwhagen $O$ : Sensory hyperreactivity - a possible mechanism underlying cough and asthma-like symptom. Allergy 1998, 53:1208-1212

12. Johansson A, Lowhagen O, Millqvist E, Bende M: Capsaicin inhalation test for identification of sensory hyperreactivity. Respir Med 2002, 96:731-735.

13. Ternesten-Hasseus E, Lowhagen O, Millqvist E: Quality of life and capsaicin sensitivity in patients with airway symptoms induced by chemicals and scents: a longitudinal study. Environ Health Perspect 2007, 115:425-429.

14. Johansson A, Millqvist E, Nordin S, Bende M: Relationship between selfreported odor intolerance and sensitivity to inhaled capsaicin: proposed definition of airway sensory hyperreactivity and estimation of its prevalence. Chest 2006, 129:1623-1628.

15. Ternesten-Hasseus E, Larsson C, Bende M, Millqvist E: Capsaicin provocation using two different inhalation devices. Respir Med 2008, 102:1784-1790.

16. Fuller $R$, Dixon $C$, Barnes P: Bronchoconstrictor response to inhaled capsaicin in humans. J Appl Physiol 1985, 58:1080-1084.

17. Karlsson J-A, Sant'Ambrogio G, Widdicombe J: Afferent neural pathways in cough and reflex bronchoconstriction. J Appl Physiol 1988, 65:1007-1023.

18. Midgren B, Hansson L, Karlsson J-A, Simonsson BG, Persson CGA: Capsaicininduced cough in humans. Am Rev Respir Dis 1992, 146:347-351.

19. Dicpinigaitis PV, Alva RV: Safety of capsaicin cough challenge testing. Chest 2005, 128:196-202.

20. Caterina M, Schumacher M, Tominaga M, Rosen T, Levine J, Julius D: The capsaicin receptor: a heat-activated ion channel in the pain pathway. Nature 1997, 389:816-823.

21. Caterina MJ, Julius D: Sense and specificity: a molecular identity for nociceptors. Curr Opin Neurobiol 1999, 9:525-530.

22. Groneberg DA, Niimi A, Dinh QT, Cosio B, Hew M, Fischer A, Chung KF: Increased expression of transient receptor potential vanilloid-1 in airway nerves of chronic cough. Am J Respir Crit Care Med 2004, 170:1276-1280.

23. O'Connell F, Thomas VE, Pride NB, Fuller RW: Capsaicin cough sensitivity decreases with successful treatment of chronic cough. Am J Respir Crit Care Med 1994, 150:374-380.

24. Ternesten-Hasseus E, Farbrot A, Lowhagen O, Millqvist E: Sensitivity to methacholine and capsaicin in patients with unclear respiratory symptoms. Allergy 2002, 57:501-507.

25. Ternesten-Hasseus E, Johansson K, Lowhagen O, Millqvist E: Inhalation method determines outcome of capsaicin inhalation in patients with chronic cough due to sensory hyperreactivity. Pulm Pharmacol Ther 2006, 19:172-178 
26. Sterk PJ, Fabbri LM, Quanjer PH, Cockroft DW, O'Byrne PM, Anderson SD, Juniper EF, Malo JL: Standardized challenge testing with pharmacological, physical and sensitizing stimuli in adults. Eur Respir J 1993, 6(suppl 16):53-83.

27. Crapo RO, Casaburi R, Coates AL, Enright PL, Hankinson JL, Irvin CG, Maclntyre NR, McKay RT, Wanger JS, Anderson SD, Cockcroft DW, Fish JE, Sterk PJ: Guidelines for methacholine and exercise challenge testing1999. This official statement of the American Thoracic Society was adopted by the ATS Board of Directors, July 1999. Am J Respir Crit Care Med 2000, 161:309-329.

28. Ternesten-Hasseus E, Bende M, Millqvist E: Increased capsaicin cough sensitivity in patients with multiple chemical sensitivity. $J$ Occup Environ Med 2002, 44:1012-1017.

29. Ekstrand Y, Ternesten-Hasseus E, Arvidsson M, Lofdahl K, Palmqvist M, Millqvist E: Sensitivity to environmental irritants and capsaicin cough reaction in patients with a positive methacholine provocation test before and after treatment with inhaled corticosteroids. J Asthma 2011, 48:482-489.

30. Fujimura M, Kasahara K, Kamio Y, Naruse M, Hashimoto T, Matsuda T: Female gender as a determinant of cough threshold to inhaled capsaicin. Eur Respir 」 1996, 9:1624-1626.

31. Kastelik JA, Thompson RH, Aziz I, Ojoo JC, Redington AE, Morice AH: Sexrelated differences in cough reflex sensitivity in patients with chronic cough. Am J Respir Crit Care Med 2002, 166:961-964.

32. Chung KF: Chronic 'cough hypersensitivity syndrome': a more precise label for chronic cough. Pulm Pharmacol Ther 2011, 24:267-271.

33. Millqvist E: The airway sensory hyperreactivity syndrome. Pulm Pharmacol Ther 2011, 24:263-266

34. Morice AH, Faruqi S, Wright CE, Thompson R, Bland JM: Cough hypersensitivity syndrome: a distinct clinical entity. Lung 2011, 189:73-79.

35. Doherty MJ, Mister R, Pearson MG, Calverly PMA: Capsaicin responsiveness and cough in asthma and chronic obstructive pulmonary disease. Thorax 2000, 55:643-649.

36. Morice AH, Fontana GA, Belvisi MG, Birring SS, Chung KF, Dicpinigaitis PV, Kastelik JA, McGarvey LP, Smith JA, Tatar M, Widdicombe J: ERS guidelines on the assessment of cough. Eur Respir J 2007, 29:1256-1276.

37. Millqvist $E$, Bende $M$, Löwhagen $O$ : Quality of life and capsaicin sensitivity in patients with sensory airway hyperreactivity. Allergy 2000, 55:540-545.

38. Morice AH, Geppetti P: Cough. 5: The type 1 vanilloid receptor: a sensory receptor for cough. Thorax 2004, 59:257-258.

39. Sanu A, Eccles R: Postnasal drip syndrome. Two hundred years of controversy between UK and USA. Rhinology 2008, 46:86-91.

40. Avidan B, Sonnenberg A, Schnell TG, Sontag SJ: Temporal associations between coughing or wheezing and acid reflux in asthmatics. Gut 2001 49:767-772.

41. Morice AH, Kastelik JA: Cough. 1: Chronic cough in adults. Thorax 2003, 58:901-907.

42. Dicpinigaitis PV: Cough: an unmet clinical need. Br J Pharmacol 2011, 163:116-124.

43. Irwin RS, Baumann MH, Bolser DC, Boulet LP, Braman SS, Brightling CE, Brown KK, Canning BJ, Chang AB, Dicpinigaitis PV, Eccles R, Glomb WB, Goldstein LB, Graham LM, Hargreave FE, Kvale PA, Lewis SZ, McCool FD, McCrory DC, Prakash UB, Pratter MR, Rosen MJ, Schulman E, Shannon JJ, Smith Hammond C, Tarlo SM: Diagnosis and management of cough executive summary: ACCP evidence-based clinical practice guidelines. Chest 2006, 129:1S-23S.

44. Millqvist $\mathrm{E}$, Bende $\mathrm{M}$ : Role of the upper airways in patients with chronic cough. Curr Opin Allergy Clin Immunol 2006, 6:7-11.

45. Chung KF, Pavord ID: Prevalence, pathogenesis, and causes of chronic cough. Lancet 2008, 371:1364-1374.

46. Bende M, Millqvist E: Prevalence of chronic cough in relation to upper and lower airway symptoms; the Skövde population-based study. Front Physiol 2012, 3:1-4.

47. Morice AH: The cough hypersensitivity syndrome: A novel paradigm for understanding cough. Lung 2009, 188:87-90.

doi:10.1186/1745-9974-9-5

Cite this article as: Ternesten-Hasséus et al: Capsaicin sensitivity in patients with chronic cough- results from a cross-sectional study. Cough 2013 9:5.

\section{Submit your next manuscript to BioMed Central and take full advantage of:}

- Convenient online submission

- Thorough peer review

- No space constraints or color figure charges

- Immediate publication on acceptance

- Inclusion in PubMed, CAS, Scopus and Google Scholar

- Research which is freely available for redistribution 